\title{
An unusual cause for shock in dengue fever
}

\section{A S D Liyanage ${ }^{1}$, M T G J Kumara ${ }^{1}$, D K Rupasinghe ${ }^{1}$, S Sutharshan ${ }^{1}$, B D Gamage ${ }^{1}$, A Kulathunga ${ }^{2}$, W M M de Silva ${ }^{1}$}

Ceylon Medical Journal 2011; 56: 120-121

\section{Introduction}

Dengue shock syndrome carries poor prognosis. Shock in dengue may not always be due to shock syndrome. Spontaneous splenic rupture can mimic shock syndrome, which is rare but potentially fatal. We report a case of spontaneous splenic rupture in a dengue patient treated by emergency splenectomy, which was curative.

\section{Case report}

An otherwise healthy 30 -year old man was admitted with six days fever and malaise. He was haemodynamically stable on admission and capillary refilling was less than 2 seconds. His platelet count was $99 \times 106 / \mathrm{ml}$ and packed cell volume was $43 \%$. On the following day he experienced abdominal discomfort and distension. Few hours later patient collapsed and systolic blood pressure was 80 $\mathrm{mmHg}$.

His haemoglobin dropped from $15.6 \mathrm{~g} / \mathrm{dl}$ to $6 \mathrm{~g} / \mathrm{dl}$ and he went into refractory shock despite resuscitation with blood and volume expanders in the intensive care setting. Further, he developed features of intra-abdominal hypertension with anuria and low cardiac output. Ultrasonography showed gross ascites and hepatomegaly. Needle paracentesis showed frank blood in the peritoneal cavity. Resuscitative laparotomy was decided upon.

There was about 3 liters of blood in the peritoneal cavity on laparotomy. Splenic capsule was found to have torn exposing the raw oozing surface. Splenectomy was performed and the patient recovered and went home after 14 days of hospital stay. Pathological examination of the

${ }^{1}$ University Surgical Unit, Colombo South Teaching Hospital, ${ }^{2}$ Medical Unit, Colombo South Teaching Hospital, Sri Lanka.

Correspondence: ASDL, e-mail: <liyanagealoka@yahoo.com>. Received 18 September 2010 and accepted 26 February 2011. Competing interests: none declared. 
spleen showed capsular tear with normal parenchymal architecture. Dengue viral serology (ELISA Ig G and Ig M) was positive in two samples. Epstein-Bar and Cytomegalo viral serology were negative.

\section{Discussion}

Dengue fever is currently the most serious public health issue in Sri Lanka. It has claimed 213 deaths, and more than 29,000 infected cases from January to September 2010 [1]. Approximately 50 to 100 million people are infected with the virus per annum worldwide [2].

Direct injury by dengue virus to various organs, such as skin, lung, heart muscles, bone marrow, lymph nodes and liver has been documented [3]. The spleen, which is frequently congestive, bears subcapsular haematomas in $15 \%$ of cases [4]. Splenic rupture is rare but a potentially fatal complication of dengue. It may be a spontaneous rupture or following minor trauma, which is usually unnoticed. Typical presentation is acute, but progressive forms have been described. The splenic rupture can be misdiagnosed due to misinterpretation of the shock syndrome in dengue haemorrhagic fever [5]. Failure of early intervention can be fatal. The index case had a sudden collapse followed by features of abdominal hypertension and refractory shock.

The diagnosis of splenic rupture could be made by abdominal ultrasound or CT scan. The bed-side ultrasonography of the index case however failed to show evidence of splenic rupture but gross ascites. General condition of the patient hindered computerised tomography. Therefore diagnostic needle paracentesis was performed which showed frank haemoperitoneum.

Haemodynamic stability and the general condition of the patient determine the treatment option in splenic rupture. Conservative management has been used successfully for traumatic rupture of the spleen and several teams have reported good results in patients with infectious mononucleosis [6]. In cases of transfusions larger than two red cell concentrates or clinical aggravation, a splenectomy is necessary [7]. Our patient had refractory shock with developing abdominal hypertension despite transfusion of 6 units of blood, which indicated continuing exsanguination. Hence resuscitative laparotomy was obligatory.

\section{References}

1. Epidemiology unit, Ministry of Health and Nutrition, Sri Lanka. September 2010.

2. Seravali MRM. Spontaneous splenic rupture due to dengue fever: Report of two cases. Brazil Journal of Infectious Diseases 2008; 12: 538-40.

3. Srichaikul T, Punyagupta S, Kanchanapoom T, et al. Hemophagocytic syndrome in dengue hemorrhagic fever with severe multiorgan complications. Journal of Medical Association of Thailand 2008; 91:104-9.

4. Bhamarapravati N, Tuchinda P, Boonyapaknavik V. Pathology of Thailand haemorrhagic fever: a study of 100 autopsy cases. Annals of Tropical Medical Parasitology 1967; 61: 500-10.

5. Miranda LEC, Miranda SJC, Rolland M. Case report: spontaneous rupture of the spleen due to dengue fever. The Brazilian Journal of Infectious Diseases 2003; 7: 423-5.

6. Imbert P, Sordet D, Hovette P, Touze JE. Spleen rupture in a patient with dengue fever. Annals of Tropical Medical Parasitology 1993; 44: 327-8.

7. Rapp C, Debord T, Imbert P, Lambotte O, Roué R. Splenic rupture in infectious disease: splenectomy or conservative treatment? Report of three cases. La Revue Médecine Interne 2002; 23: 85-91. 